Original Research Paper

\title{
A Novel Linear Array Antenna Based on UWB Slot Antenna
}

\author{
Faten Ben Ghenaya, Ridha Ghayoula and Ali Gharsallah \\ Unit of Research in High Frequency Electronic Circuits and Systems, \\ Faculty of Mathematical, Physical and Natural Sciences of Tunis, \\ Tunis El Manar University, Campus Universitaire Tunis-El Manar-2092, Tunis, Tunisia
}

\author{
Article history \\ Received: 07-11-2015 \\ Revised: 22-01-2016 \\ Accepted: 30-01-2016 \\ Corresponding Author: \\ Faten Ben Ghenaya, \\ Unit of Research in High \\ Frequency Electronic Circuits \\ and Systems, Faculty of \\ Mathematical, Physical and \\ Natural Sciences of Tunis, \\ Tunis El Manar University, \\ Campus Universitaire Tunis-El \\ Manar-2092, Tunis, Tunisia \\ Email: benghenayafaten@yahoo.fr
}

\begin{abstract}
This paper introduces the novel Ultra-Wide Band (UWB) antennas for UWB applications. We used two different structures, the first is fed by micro-strip line and the second is a compact coplanar waveguide fed planar slot antenna. These designs are a small on planar antenna. The substrate used is FR4 that have the characteristics following: Permittivity $\varepsilon_{\mathrm{r}}$ $=4.4$ Impulse Radio Ultra Wide Band systems (IR-UWB). The frequency central is $5.6 \mathrm{GHz}$ and shows good characteristics for IR-UWB. The radiation pattern and gain are simulated and we compared between the different results we have obtained.
\end{abstract}

Keywords: Wireless Communications, UWB Antenna, Linear Antenna Array

\section{Introduction}

In the Internet development, wireless communications with mobile vehicles becomes a new challenge because most computers and almost all "mobile" devices (such as mobile phones) have means for connection to one or more types of wireless networks such as WiFi, Bluetooth or infrared (Sabattier, 2008). So, the necessity of high data rates wireless communication becomes more and more urgent and various solutions have been brought forward. As a solution, we choose the UWB antenna because she makes it possible to attain speeds of several hundreds of megabits per second, while retaining a limited cost and complexity (Blefari-Melazzi et al., 2002).

Currently, a plurality of antenna structures have been designed to satisfy the strong demand of wideband antennas and more miniaturization techniques and band broadening have been developed. Many technologies were reported to broaden the bandwidth: The stacked patch antennas with aperture coupled feed can provide wider bandwidth, to cover GSM1800 and UMTS in, the Microstrip stacked patches for dual-polarization have been proposed, patch elements fed with two probes with a relatively broad bandwidth have been introduced, Genetic algorithm was used to design microstrip patches operating at GSM1800 up to UMTS and for simple structure and stable performance needs, through metal dipole antenna is an usual choice.

In this article, we offer two new Ultra Wide-Band antennas for UWB applications and for communicate with mobile vehicles, we are interested exclusively on the base station and as an application, we proposed the implementation of these antennas near propose to design high gain antennas to maximize their range and minimize their number (Ahmed and Sebak, 2008).

As first proposed antenna consists of a rectangular patch with two stages and a partial plan field (Choi et al., 2004; Vuong et al., 2006).

In the rectangle, we added 2 slots to obtain high bandwidth and higher gain in the normal direction of the plane of the antenna. The inquests based on experiments and simulations are conducted. The simulation is performed using the commercially available simulation software CST Microwave Studio (CSTMS, 2008). The second antenna is a Compact Coplanar Waveguide (CPW) fed planar slot antenna (William and Nakkeeran, 2010a). This antenna possesses the above said characteristics with simple structure, less dispersion, less radiation loss and easy integration of Monolithic Microwave Integration Circuits (MMIC) (Simons, 2004). This antenna is fed by a coplanar line with a rectangular slot to ensure high bandwidth and higher gain in the normal direction of the plane of the antenna. In the second part of the article, we presented the antenna networks and as example we utilize simulation of linear antenna array. This article is organized as follows: In section 2, we presented the UWB antenna, section 3 presented the two structures proposed and simulation, section 4 presented the linear Array and the simulation results and, finally, section 5 makes conclusions. 
Table 1. The frequency band for these applications

\begin{tabular}{ll}
\hline Frequency Band & Applications \\
\hline 24 and $77 \mathrm{GHz}$ & applications related to vehicle \\
$<1 \mathrm{GHz}$ & GPR radar and radar \\
$1.99-10.6 \mathrm{GHz}$ & Medical applications (imaging) \\
$3.1-10.6 \mathrm{GHz}$ & Wireless communications \\
& systems and applications \\
& related to the localization \\
\hline
\end{tabular}

\section{Ultra Wide Band Antenna}

The techniques of Ultra Wide Band (UWB) were paid the most attention to multiple advantages, such as higher data rates, operational safety, low interference existing systems and immunity to the cancellation of the increase in multiple communications.

The definition of Ultra Broadband given by the FCC (Federal Communication commission) in February 2002 is as follows. A signal is Ultra Wide Band if its band width is at least $500 \mathrm{MHz}(-10 \mathrm{~dB})$ (FCC NEWS, 2002).

There are three major categories of primary applications for UWB systems: The detection, the location-based and wireless communications. The first two do not require a large flow of information, but require good accuracy over long distances and robustness to multipath while son without communications can take advantage of very high speed short range offered by the UWB technology.

The frequency bands for these applications are detailed in the Table 1.

UWB promises indeed reach speeds of hundreds of megabits per second, while maintaining complexity and limited costs. Nature and its impulse bandwidth also give it a good resistance to jamming and multiple paths, which makes it very adapted for indoor use. The purpose of this article is to study and develop two new UWB antenna structures for use in telecommunication systems.

Lately, a new version of Ultra Wide Band monocone antenna was conceived for UWB channel measurement (Bories et al., 2003; Saad-Bin-Alam and Moury, 2014) and a Vivaldi antenna and the transient responses of a logarithmic periodic dipole are presented for the characterization of a UWB antenna (Sorgel et al., 2003).

\section{Antennas Geometry}

In this section, we use two types of antennas: The UWB with two slots (Fig. 1) and triangular slot antenna (Fig. 2).

The simulation is carried out using the commercially available simulation software CST Microwave Studio (CSTMS, 2008).

The return loss and radiation pattern of the two antennas of horizontal plane are shown in Fig. 2, 3, 5 and 6.

\section{First Configuration: The UWB Antenna with two Slots}

In Fig. 1, we present a new UWB patch antenna which consists of a rectangular patch with two slots, two steps and a partial ground plane (Vuong et al., 2007). This antenna is fed by microstrip line.

The proposed antennas have been printed on a FR4 epoxy substrate with permittivity $\left(\varepsilon_{\mathrm{r}}=4.4, \tan \delta=\right.$ 0.0009 ) and thickness $\mathrm{h}=1.6 \mathrm{~mm}$.

The size of this antenna with two slots in Fig. 1 is around $35 \mathrm{~mm}\left(\mathrm{~L}_{\mathrm{sub}}\right) \times 30 \mathrm{~mm}\left(\mathrm{~W}_{\mathrm{sub}}\right)$.

The antenna is printed in the front of substrate FR4 with the compact dimensions of $15 \times 14.5 \mathrm{~mm}^{2}$ and is feed by a $50 \Omega$ microstrip line printed on a partial ground plane.

The dimensions of the slot and of the ground plane are $\left(11 \times 0.5 \mathrm{~mm}^{2}\right)$ and $\left(30 \times 11.5 \mathrm{~mm}^{2}\right)$ respectively in this study. The parameters of the antenna are the following: $\mathrm{L}_{\mathrm{p}}=$ $14.5, \mathrm{~W}_{\mathrm{p}}=15, \mathrm{~L}_{\mathrm{sl}}=5, \mathrm{~W}_{\mathrm{sl}}=0.5, \mathrm{~L}_{\mathrm{st} 1}=1, \mathrm{~W}_{\mathrm{st} 1}=1.5, \mathrm{~L}_{\mathrm{st} 2}=$ $1.5, \mathrm{~W}_{\mathrm{st} 2}=1.5, \mathrm{~W}_{\mathrm{c}}=1, \mathrm{~L}_{\mathrm{f}}=12.5$ and $\mathrm{W}_{\mathrm{f}}=3.2 \mathrm{~mm}$.

We use commercially available simulation CST Microwave Studio to realize the antenna. The return loss (Fig. 2) and radiation pattern (Fig. 3) of the UWB antenna with two slots are shown.

\section{Second Configuration: The Triangular Slot Antenna}

Figure 4 presents a UWB patch antenna in the form of rectangle fed by a Coplanar Waveguide (CPW) in a rectangular slot to ensure high bandwidth and a higher gain in the normal direction of the plane of the antenna (William and Nakkeeran, 2010b).

This antenna has been printed on a FR4 epoxy substrate with thickness $\mathrm{h}=1.6 \mathrm{~mm}$ and permittivity $\left(\varepsilon_{\mathrm{r}}=\right.$ $4.4, \tan \delta=0.0009$ ).

Figure 4 shows the dimensions of the antenna proposed who are: The length $(\mathrm{L})$ and width $(\mathrm{W})$ of antenna are $28 \times 21 \mathrm{~mm}$, the length $\left(\mathrm{L}_{1}\right)$ and width $\left(\mathrm{W}_{1}\right)$ of the slot are $13.5 \times 14 \mathrm{~mm}$, the feed gap distance (d) is $1.1 \mathrm{~mm}$, the height of the tuning stub $(\mathrm{H})$ is $5.4 \mathrm{~mm}$ and the length of the slot in the tuning stub $\left(\mathrm{L}_{2}\right)$ is $18 \mathrm{~mm}$.

The $50 \Omega$ characteristic impedance CPW feed is designed with fixed feed line width of 2.4 and $0.5 \mathrm{~mm}$ ground gap.

\section{Different Characteristics for the 2 Antennas}

As summary, the antennas have the following characteristics, in order to more easily in power before their advantages and disadvantages.

Figure 7 represents the return loss of the two antennas: UWB antenna with two slots and the triangular slot antenna.

Table 2 summarizes the different characteristics for the two antennas.

In Fig. 8, we have shown the input impedance of the UWB antenna with two slots over the bandwidth of 5 to $8 \mathrm{GHz}$. The graph shows input impedance fluctuates throughout the bandwidth of 5 to $8 \mathrm{GHz}$. the imaginary part of the impedance between $20 \Omega$ and about $-40 \Omega$ gold the real part of the impedance varies between 70 and $20 \Omega$ about. 


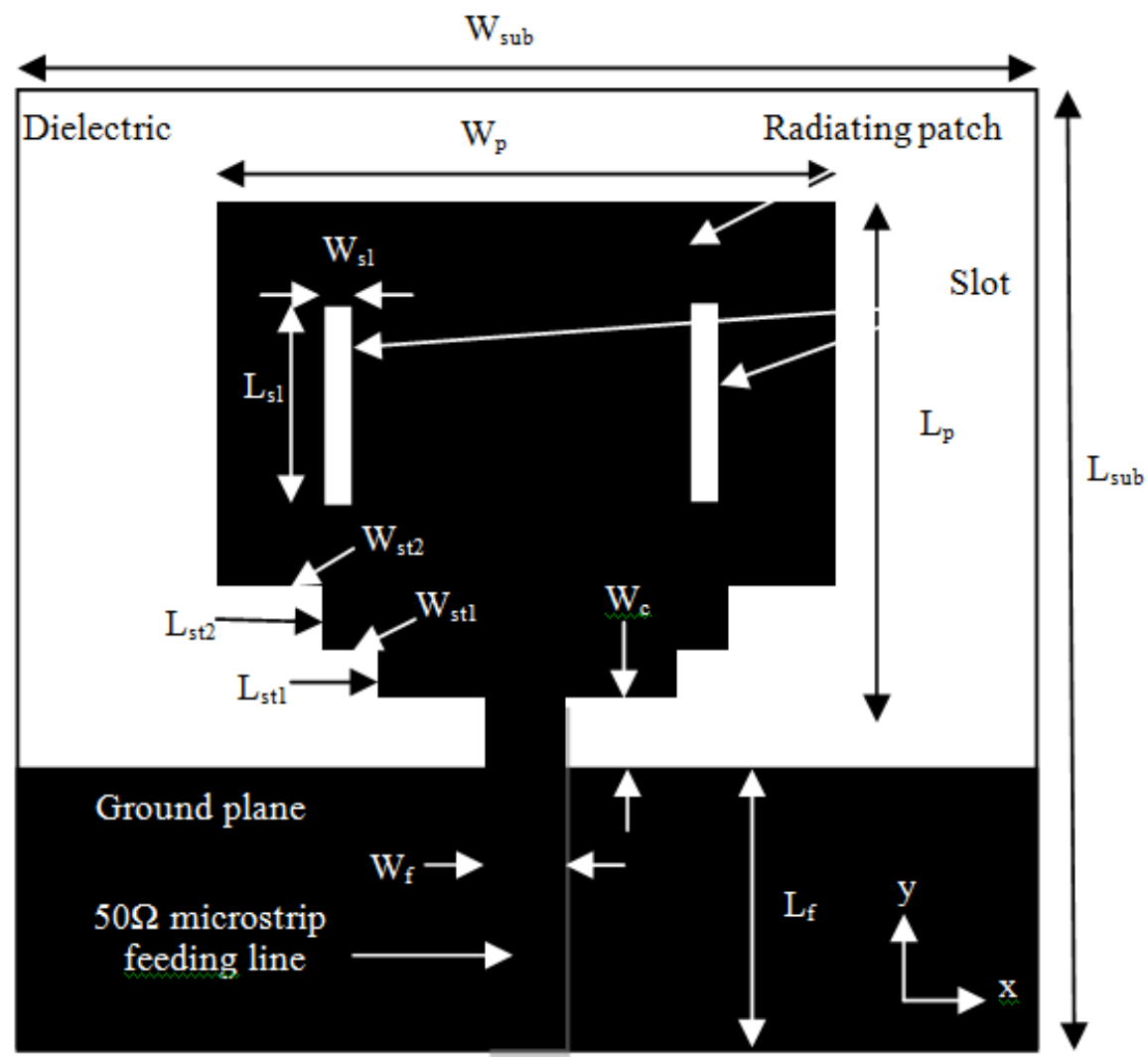

Fig. 1. Geometry of the UWB antenna with two slots

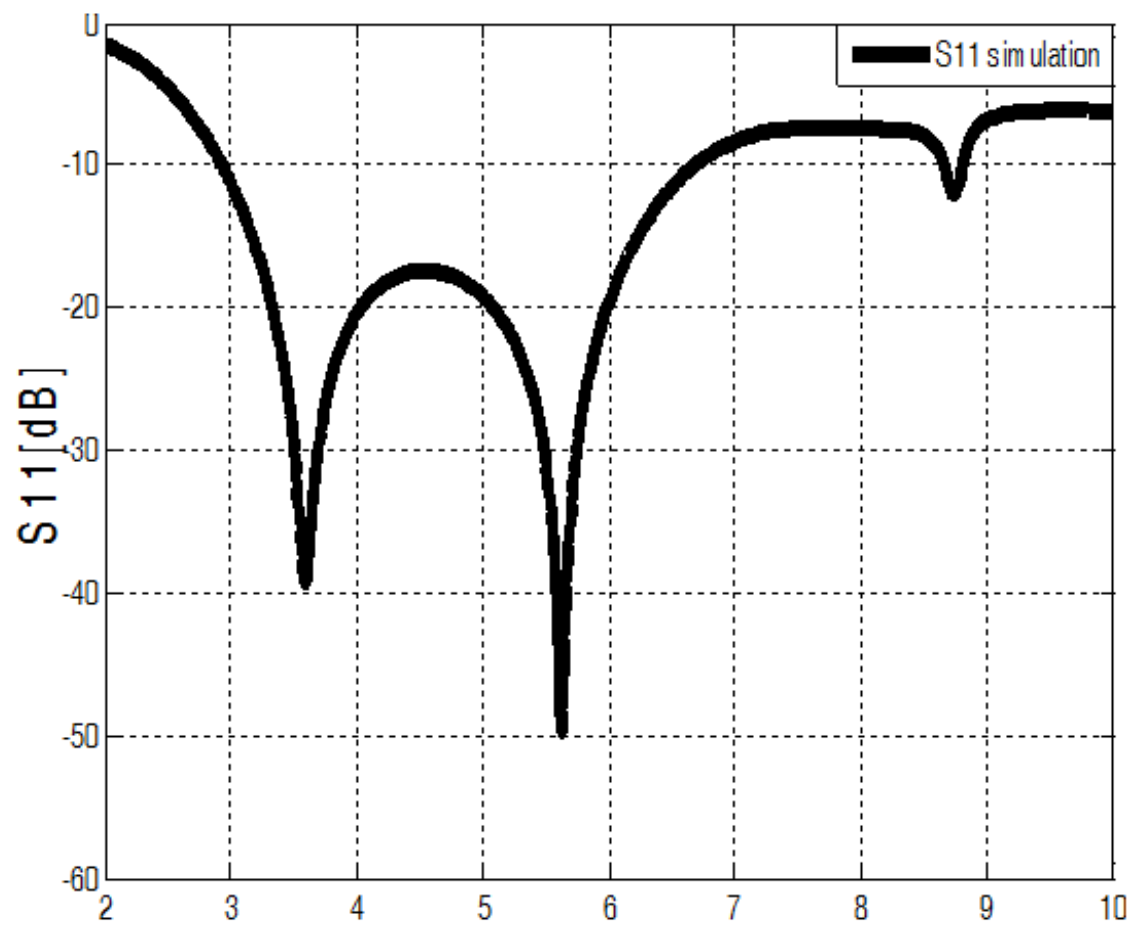

Fig. 2. Return loss of the UWB antenna with two slots 

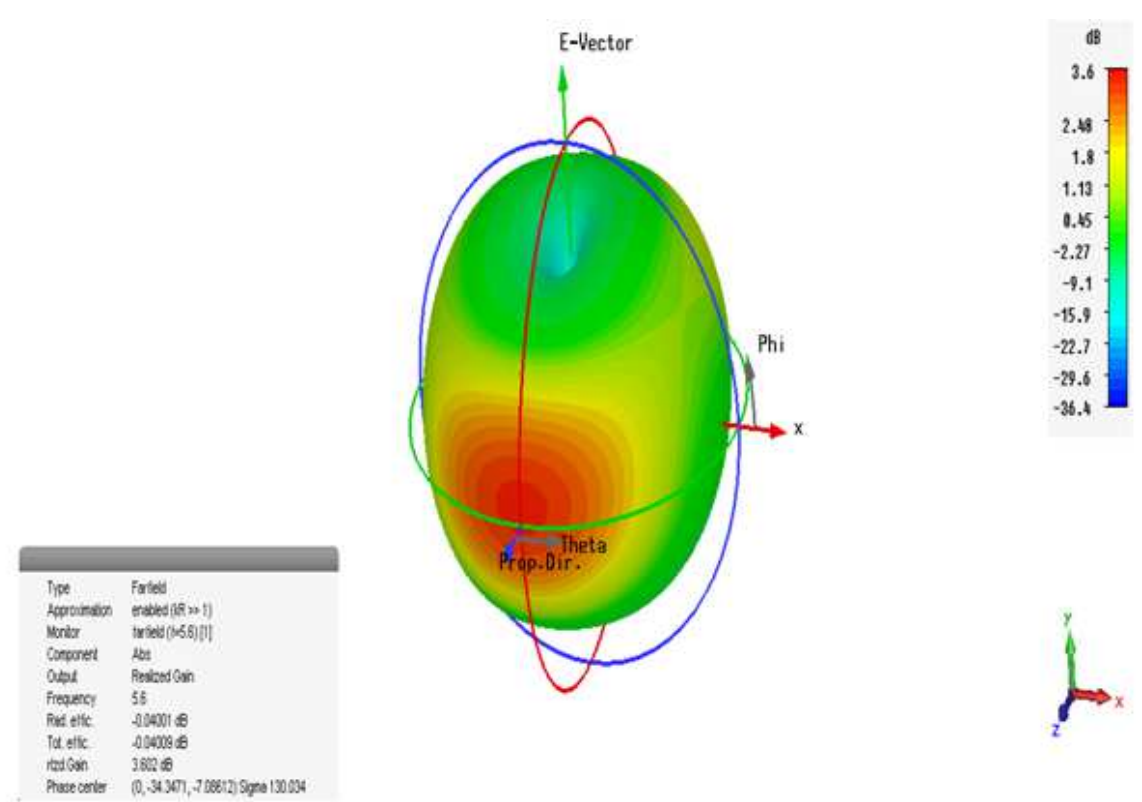

Fig. 3. Radiation pattern of the UWB antenna with two slots in 3d

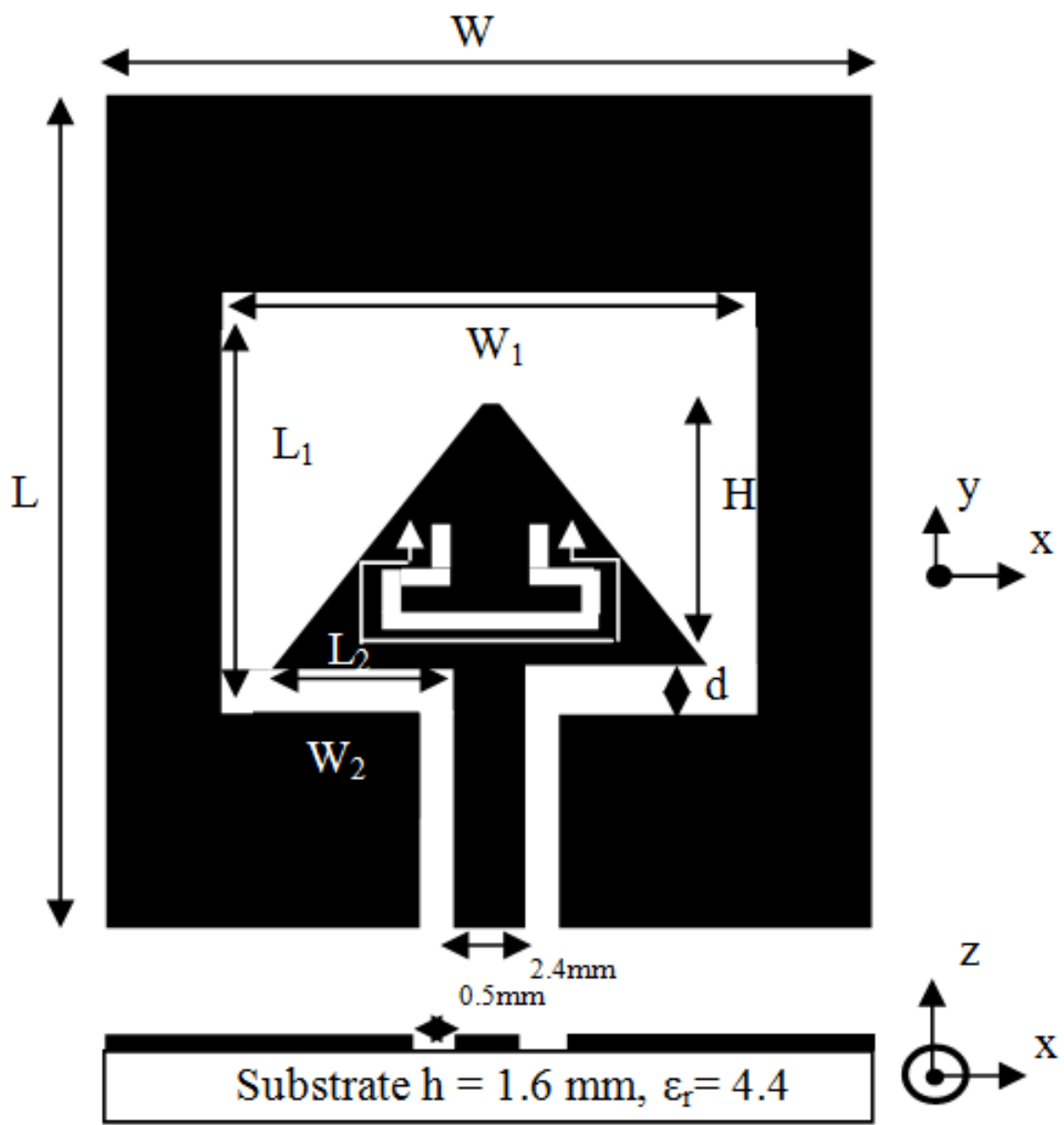

Fig. 4. Geometry of the triangular slot antenna 


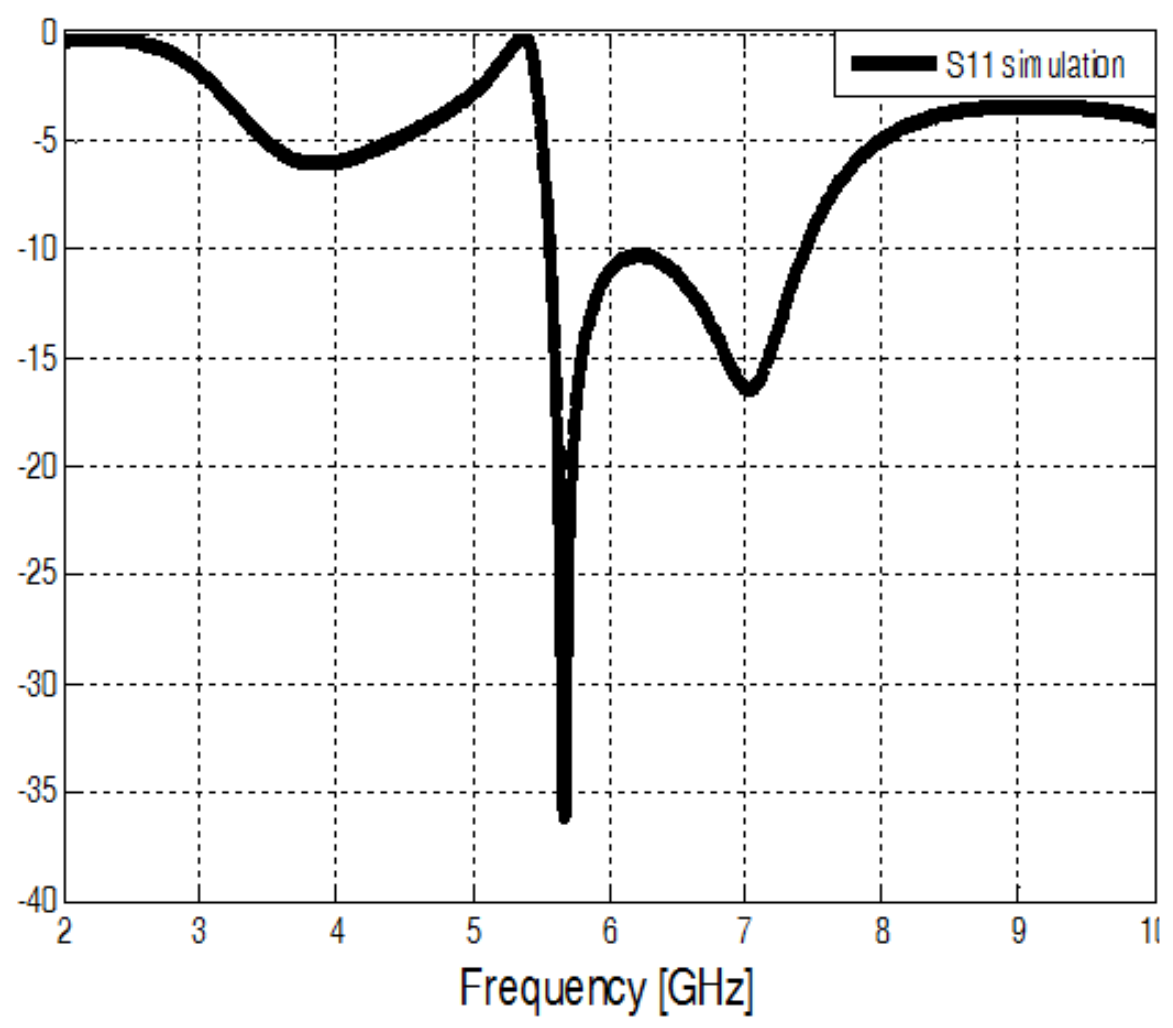

Fig. 5. Return loss of the triangular slot antenna
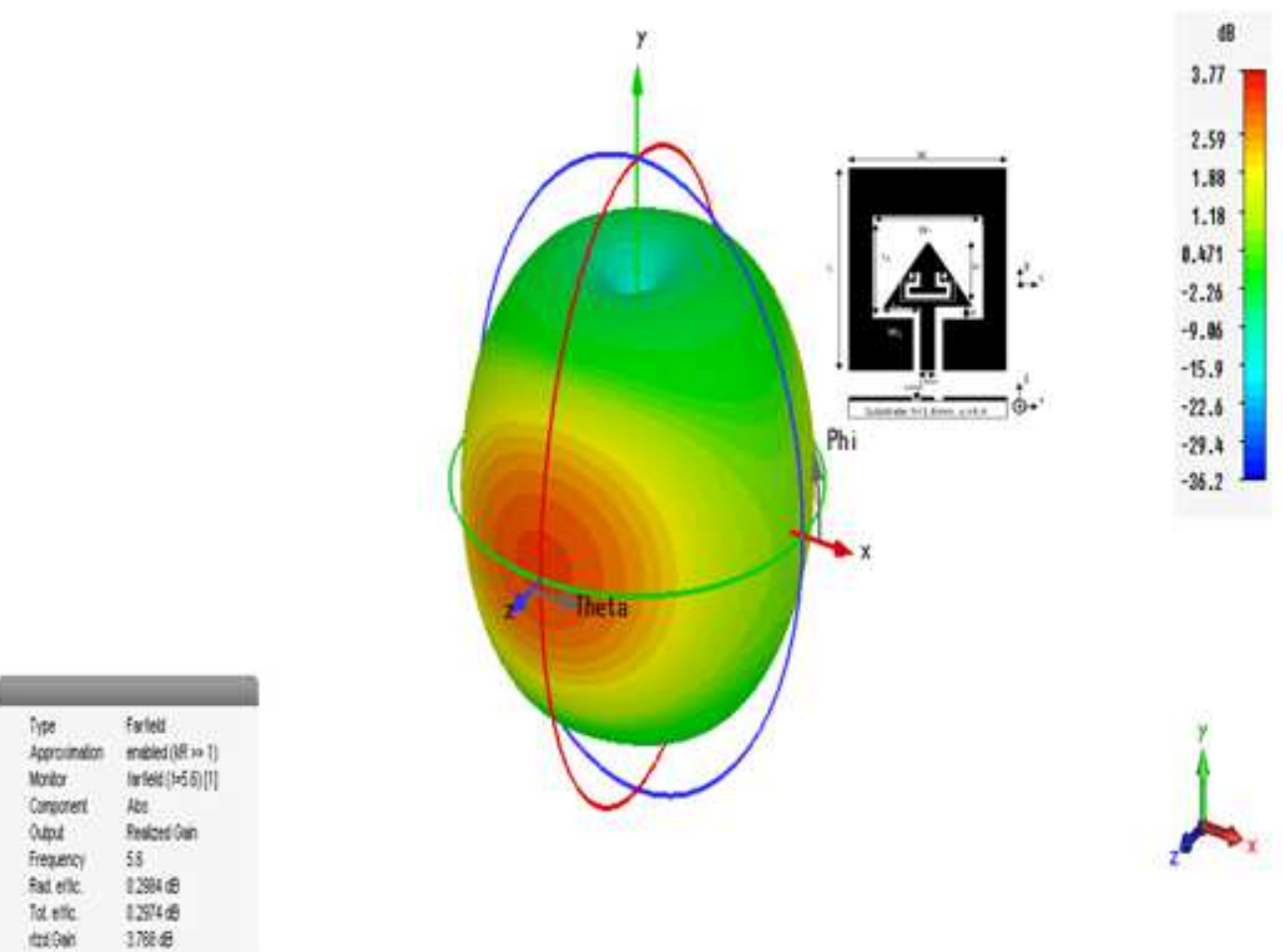

Fig. 6. Radiation pattern of the triangular slot antenna 


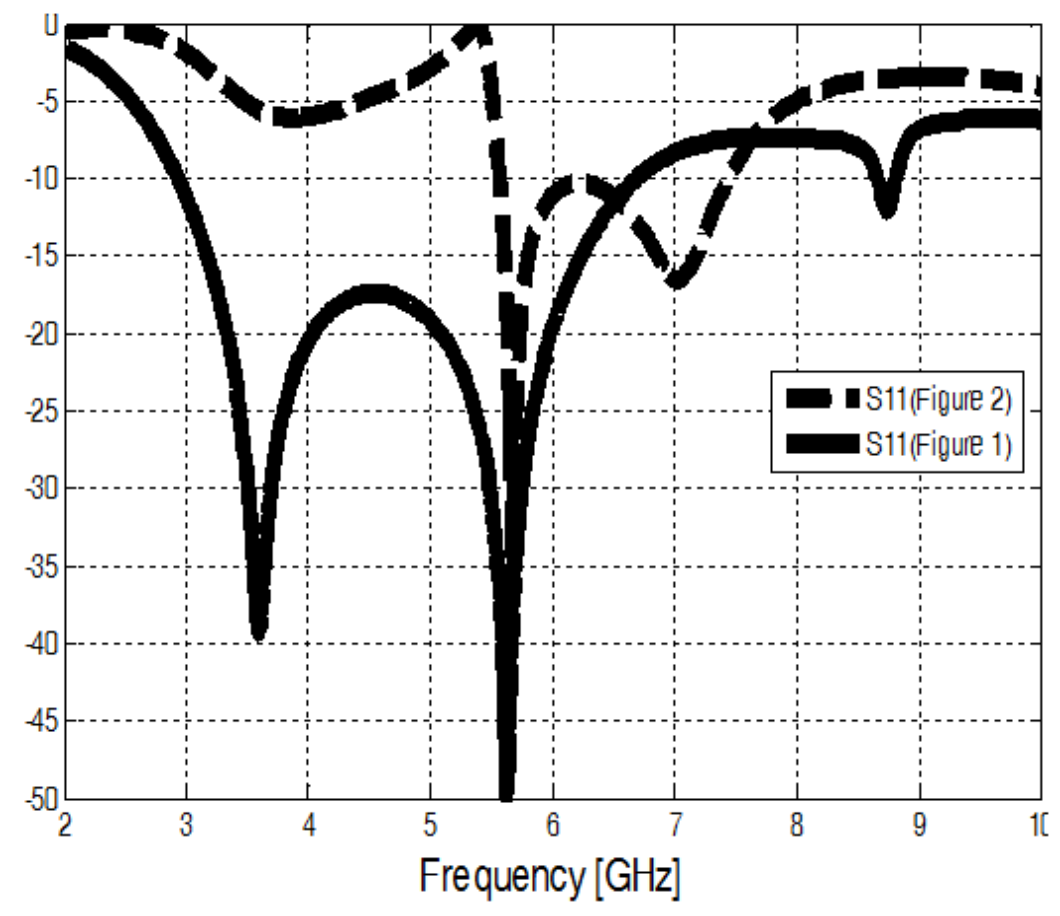

Fig. 7. Return loss of the UWB antenna with two slots and the triangular slot antenna

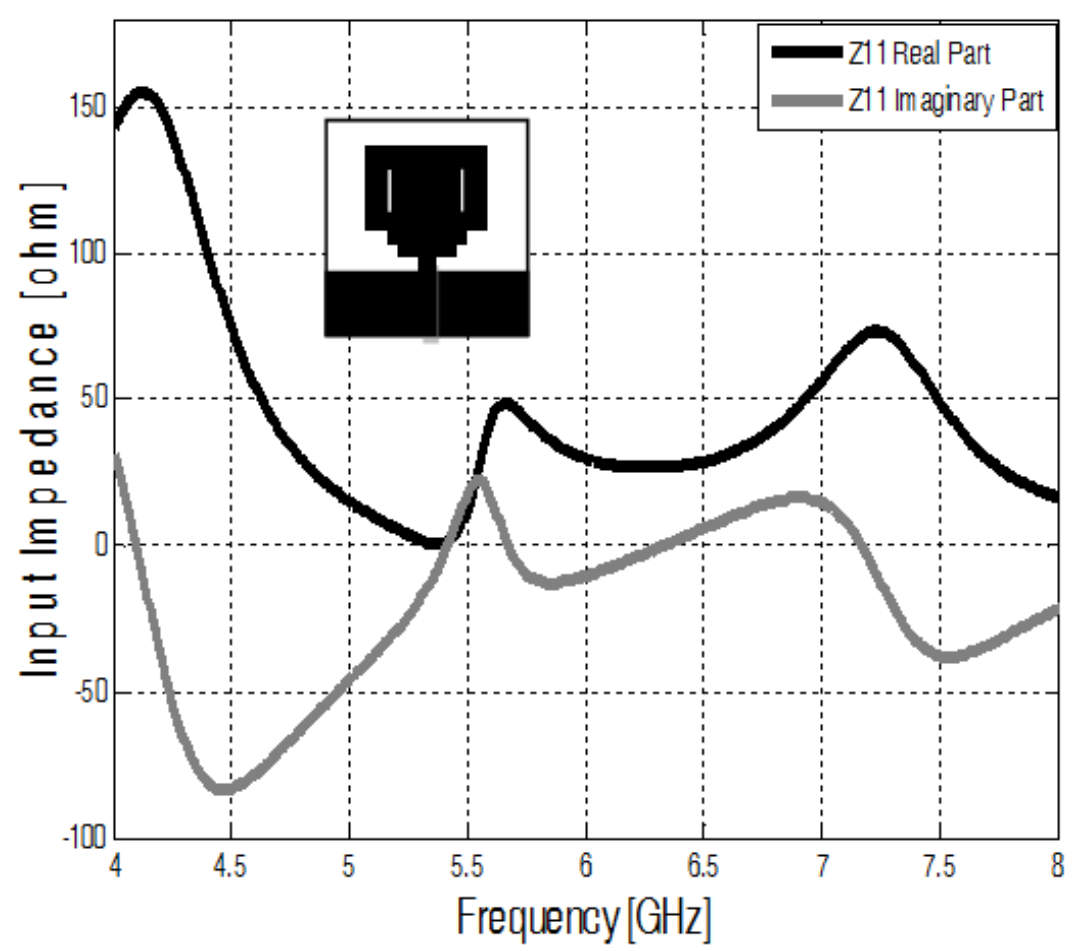

Fig. 8. Simulated real and imaginary input impedance

In Fig. 9 we have show the input impedance of the triangular slot antenna over the bandwidth between 5 and 8 GHz. The graph shows input impedance fluctuating across the entire bandwidth from 5 to $8 \mathrm{GHz}$. The real part of impedance varies between $110 \Omega$ and about $30 \Omega$, whereas the imaginary part varies between $40 \Omega$ and about $-50 \Omega$. 


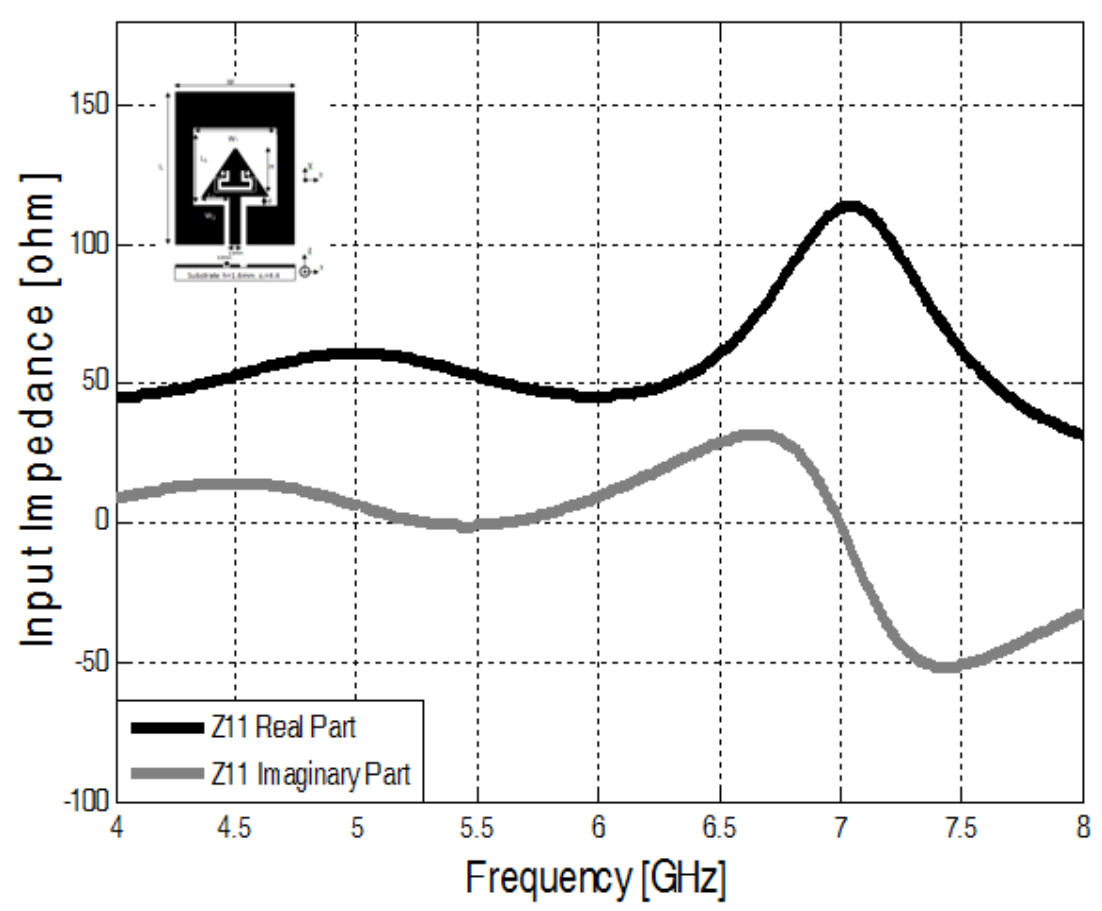

Fig. 9. Simulated real and imaginary input impedance

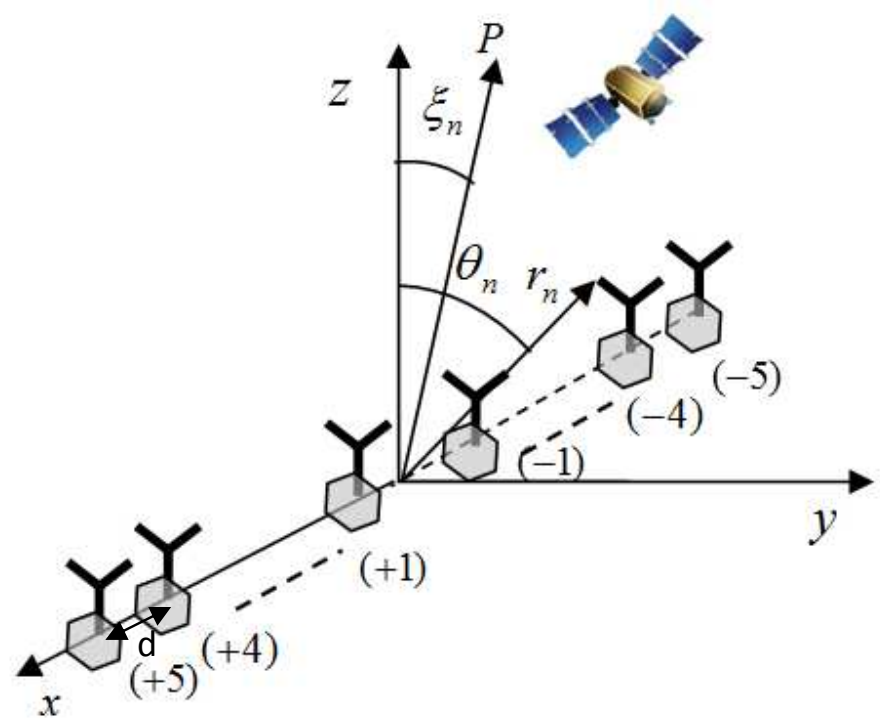

Fig. 10. Linear antennas array

Table 2. Different characteristics for the 2 antennas

\begin{tabular}{lll} 
& The UWB antenna with two slots & The triangular slot antenna \\
\hline Size & $(35 \times 30) \mathrm{mm}^{2}$ & $(35 \times 30) \mathrm{mm}^{2}$ \\
Band-width $(\mathrm{GHz})$ & 3.750 & 2.012 \\
Input Impedance $(\Omega)$ & 50.53 & 49.56 \\
Gain $(\mathrm{dB})$ & 3.642 & 3.771 \\
Directivity $(\mathrm{dBi})$ & 3.472 & 3.471 \\
Angular width at $3 \mathrm{~dB}$ in the E plane & $75.6^{\circ}$ & $96^{\circ}$ \\
Radiation pattern & Stable and symmetrical in the E plane & Stable and symmetrical in the E plane \\
Polarization & Vertical & Vertical \\
\hline
\end{tabular}




\section{Antenna Array}

An antenna array is a set of antennas separate and have a fed synchronously antennas. That is to say a phase difference between the two current pairs of antennas is fixed (Kin and Rahmat-Saimu, 2013). In our paper, we are interested in the linear array. Linear array geometry is most frequently used in the design of antenna arrays. This is a set of $\mathrm{N}$ elementary sources arranged according to a given axis and spaced in pairs by the distance d (Fig. 10) (Singh et al., 2013).

In the azimuth plane, the far-field radiation function is following axis $\mathrm{Ox}$, as we already know from Equation 1.

The angular distribution of the field is independent of the distance $r$. For a typical antenna element, the far electric field is:

$$
E_{n}(r) \cong-j \varpi \mu \frac{e^{-j \beta r}}{4 \pi r} f_{n}(\theta, \phi)
$$

The angular-dependent vector $f_{n}(\theta, \varphi)$ gives the directional characteristics of the $n$th element electric field (Vuong et al., 2007; William and Nakkeeran, 2010b):

$$
f_{n}(\theta, \phi)=I_{n} f(\theta, \phi)
$$

$f(\theta, \varphi)=$ Called the 'pattern function' of the element

$I_{n} \quad=$ The complex excitation of the $n$th element of the array

$$
E(r) \cong-j \varpi \mu \frac{e^{-j \beta r}}{4 \pi r} f(\theta, \phi) \sum_{n=1}^{N} I_{n} e^{j \beta r_{n} \cos \xi_{n}}
$$

Where:

$r$

$=$ The distance of the observation point from the origin

$$
\beta=\frac{2 \pi}{\lambda}
$$$$
=\text { The free space wave number }
$$$$
\omega \quad=\text { The angular frequency }
$$

$\mu \quad=$ The magnetic permeability of the space

$r_{n}, \theta_{n}$ and $\varphi n=$ The spherical coordinates of a convenient reference point of the $n$th element and $\cos \xi n=\sin \theta \sin \theta_{n} \cos (\varphi$ $\left.-\varphi_{n}\right)+\cos \theta \cos \theta_{n}$

\section{The Results for $N$ Antennas}

We used $\mathrm{n}$ antenna elements and we have put along the axis $\mathrm{Ox}$.

The $\mathrm{N}$ elements linearly are spaced by a distance $\mathrm{d}_{1}$ for the UWB antenna with two slots and $d_{2}$ for the triangle slot antenna.
Table 3. The results obtained for different numbers of antennas

\begin{tabular}{llc}
\hline & Gain $(\mathrm{dB})$ & \\
& - & The UWB antenna \\
$\mathrm{N}$ & with two slots & $\begin{array}{l}\text { The triangular } \\
\text { slot antenna }\end{array}$ \\
\hline 1 & 3.602 & 3.768 \\
2 & 7.015 & 7.246 \\
4 & 13.620 & 10.400 \\
8 & 14.830 & 14.530 \\
16 & 18.250 & 16.590 \\
20 & 19.252 & 18.420 \\
\hline
\end{tabular}

Table 4. Comparison between the two structures in a linear antenna array

\begin{tabular}{lll}
\hline & $\begin{array}{l}\text { The UWB antenna } \\
\text { with two slots }\end{array}$ & $\begin{array}{l}\text { The triangular } \\
\text { slot antenna }\end{array}$ \\
\hline Size $\left(\mathrm{mm}^{3}\right)$ & $630 * 30 * 1.92$ & $495 * 30 * 1.76$ \\
Band-width $(\mathrm{GHz})$ & 3.75 & 2.012 \\
Gain $(\mathrm{dB})$ & 18.25 & 16.59 \\
$\begin{array}{l}\text { Angular width at } 3 \mathrm{~dB} \\
\text { in the vertical plane }\left(^{\circ}\right)\end{array}$ & 74.3 & 73.8 \\
$\begin{array}{l}\text { Angular width at } 3 \mathrm{~dB} \\
\text { in the horizontal plane }\left(^{\circ}\right)\end{array}$ & 5.6 & 7.9 \\
\begin{tabular}{l} 
Side lobe level $(\mathrm{dB})$ \\
\hline
\end{tabular} & -6.5 & -2.5 \\
\hline
\end{tabular}

In the (Table 3), all results of simulations of the linear array of two antennas are summarized.

$\mathrm{d}_{1}=40, \mathrm{~d}_{2}=31 \mathrm{~mm}$, we saw that the gain increase with increasing numbers of antennas.

\section{Comparison between the two Structures}

To satisfy the UWB that requires strong antenna gain, we studied two types of structure in a linear antenna array.

Table 4 illustrates the main characteristics of these two solutions.

After the table, we saw the results obtained for the two structures are nearly equal, except that the first antenna gets a wideband and a higher gain.

\section{Conclusion}

In this study, we presented two novels UWB slot antenna with minimum size and better impedance matching. The first configuration of the proposed UWB antenna is a rectangular patch with two slots and two stages and a partial ground plane. The second antenna consists of coplanar fed slot antenna Compact Planar Waveguide (CPW). Due to its very wide bandwidth, these antennas can be considered as a potential candidate for cost effective UWB applications. But in many applications such as communication long distance, it is necessary to design highly directional antennas, so with a high gain.

Hence, we are set these antennas in array to increase the gain and the linear array is chosen for our application. 


\section{Acknowledgement}

We are grateful to the Unit of Research in High Frequency Electronic Circuits and Systems who supported us in the preparation of this work.

\section{Funding Information}

We have no support or funding to report.

\section{Author's Contributions}

Faten Ben Ghenaya: Conception, design and writing of computer programs for the novel Ultra-Wide Band (UWB) antennas for UWB applications.

Ridha Ghayoula: Coordination of the realization of this work.

Ali Gharsallah: Organization of the plan of this study.

\section{Ethics}

This work is new and presents unpublished material. All authors have examined and agreed the manuscript. We confirm that no ethical issues concerned.

\section{References}

Ahmed, O. and A.R. Sebak, 2008. A printed monopole antenna with two steps and a circular slot for UWB applications. IEEE Antennas Wireless Propag. Lett., 7: 411-413. DOI: 10.1109/LAWP.2008.2001026

Blefari-Melazzi, N., M.G.D. Benedetto, M. Gerla, H. Luediger and M.Z. Win et al., 2002. Guest editorial ultra-wideband radio in multiaccess wireless communications. IEEE J. Selected Areas Commun., 20: 1609-1611. DOI: 10.1109/JSAC.2002.805240

Bories, S., C. Roblin and A. Sibille, 2003. Ultrawideband monocone antenna for UWB channel measurement. University of Oulu Finland.

Choi, S.H., J.K. Park, S.K. Kim and J.Y. Park, 2004. A new ultra-wideband antenna for UWB applications. Microwave Optical Technol. Lett., 40: 399-401. DOI: $10.1002 /$ mop. 11392

CSTMS, 2008, Computer simultion technology. Framingham, MA., CST Microwave Studio.

FCC NEWS, 2002. FCC NEWS (FCC 02-48).
Kin, I. and Y. Rahmat-Saimu, 2013. EBG-dipole Array antenna creating beam-tiltfon base-station applications. Proceedings of the US National Committee of URSI National Radio Science Meeting, Jan. 9-12, IEEE Xplore Press, Boulder, CO, pp: 1-1. DOI: 10.1109/USNC-URSI-NRSM.2013.6525029

Saad-Bin-Alam, M. and S. Moury, 2014. Conversion of an Ultra-Wide-Band (UWB) antenna to dual-band antenna for Wireless Body Area Network (WBAN) applications. Proceedings of the 3rd International Conference on Informatics, Electronics and Vision, May 23-24, IEEE Xplore Press, Dhaka, pp: 1-4. DOI: 10.1109/ICIEV.2014.6850766

Sabattier, D., 2008. Première commercial: Internet à bord du train. Magazine SVM.

Simons, R.N., 2004. Coplanar Waveguide Circuits, Components and Systems, 1st Edn., John-Wiley and Sons, New York, ISBN-10: 0471463930, pp: 464.

Singh, S.K., V.B. Chandrudu and G.K. Mahanti, 2013. Synthesis of linear array antenna for fixed level of side lobe level and first null beam width using particle swarm optimization. Proceedings of the International Conference on Communications and Signal Processing, Apr. 3-5, IEEE Xplore Press, Melmaruvathur, pp: 275-279. DOI: $10.1109 /$ iccsp.2013.6577058

Sorgel, W., C. Waldshmidt and Wiesbeck, 2003. Antenna characterization for ultra-wideband communications. University of Oulu, Finland.

Vuong, T.P., A. Ghiotto, Y. Duroc and S. Tedjini, 2006. Design and characteristics of a small U-slotted planar antenna for IR-UWB. Microwave Optical Technol. Lett., 49: 1727-1731. DOI: 10.1002/mop.22515

Vuong, T.P., A. Ghlotto, Y. Duroc and S.T. Jlnl, 2007. Design and characteristics of a small U-slotted planar antenna for IR-UWB. Microwave Optical Technol. Lett., 49: 1727-1731. DOI: 10.1002/mop.22515

William, J. and R. Nakkeeran, 2010a. CPW-Fed UWB slot antenna with triangular tuning stub. Int. J. Comput. Electrical Eng., 2: 788-792.

William, J. and R. Nakkeeran, 2010b. A new UWB slot antenna with rejection of WiMAX and WLAN bands. ACES J. 